\title{
Mecoprop (MCPP) removal in full-scale rapid sand filters at a groundwater-based waterworks
}

\author{
Hedegaard, Mathilde Jørgensen; Arvin, Erik; Corfitzen, Charlotte B.; Albrechtsen, Hans-Jørgen
}

Published in:

Science of the Total Environment

Link to article, DOI:

10.1016/j.scitotenv.2014.08.052

Publication date:

2014

Link back to DTU Orbit

Citation (APA):

Hedegaard, M. J., Arvin, E., Corfitzen, C. B., \& Albrechtsen, H-J. (2014). Mecoprop (MCPP) removal in full-scale rapid sand filters at a groundwater-based waterworks. Science of the Total Environment, 499, 257-264. https://doi.org/10.1016/j.scitotenv.2014.08.052

\section{General rights}

Copyright and moral rights for the publications made accessible in the public portal are retained by the authors and/or other copyright owners and it is a condition of accessing publications that users recognise and abide by the legal requirements associated with these rights.

- Users may download and print one copy of any publication from the public portal for the purpose of private study or research.

- You may not further distribute the material or use it for any profit-making activity or commercial gain

- You may freely distribute the URL identifying the publication in the public portal 
This is a post print of: Hedegaard, M. J., Arvin, E., Corfitzen, C. B., Albrechtsen, H.-J., 2014. Mecoprop (MCPP) removal in full-scale rapid sand filters at a groundwater-based waterworks. Science of the Total Environment (2014), pp. 257-264. Publisher's version is available on: http://dx.doi.org/10.1016/j.scitotenv.2014.08.052

\section{Mecoprop (MCPP) removal in full-scale rapid sand filters at a groundwater-based waterworks}

Mathilde J. Hedegaard ${ }^{1, *}$, Erik Arvin ${ }^{1}$; Charlotte B. Corfitzen ${ }^{1}$; Hans-Jørgen Albrechtsen ${ }^{1}$

${ }^{1}$ DTU Environment, Technical University of Denmark (DTU), Miljoevej, Building 113, DK-2800 Kgs. Lyngby, Denmark

*Corresponding author: telephone (+45) 4525 1478, Email: mjhe@env.dtu.dk

Article published in Science of the Total Environment 499 (2014), pp. 257-264.

http://dx.doi.org/10.1016/j.scitotenv.2014.08.052 


\section{Graphical abstract}

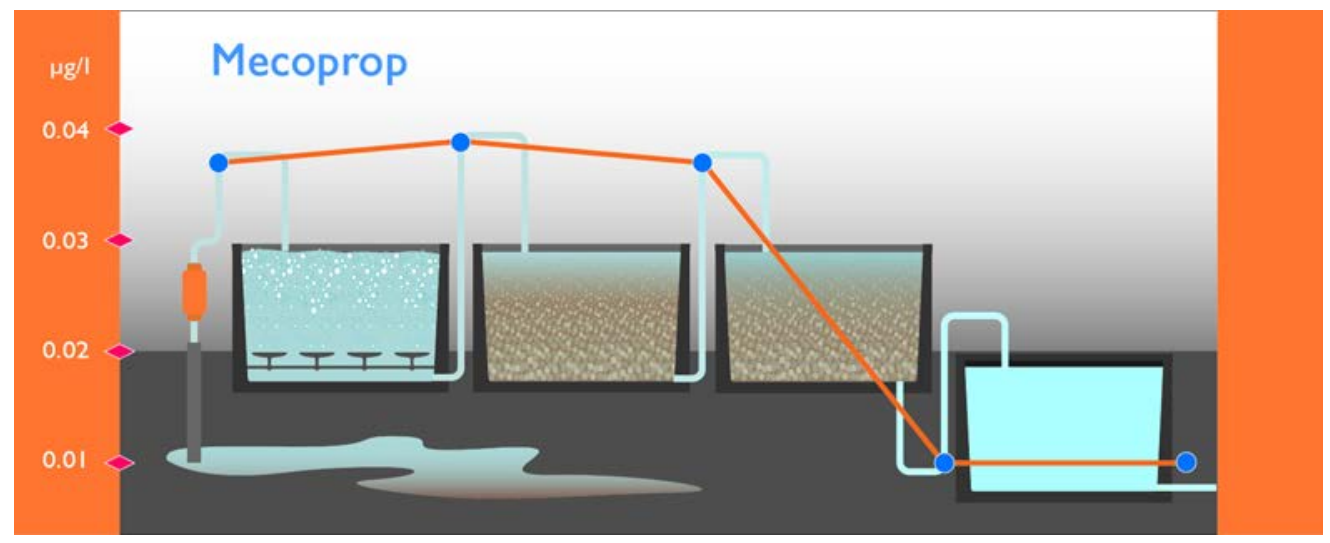

\section{Abstract}

Contamination by the herbicide mecoprop (MCPP) was detected in groundwater abstraction wells at Kerteminde Waterworks in concentrations up to $0.08 \mu \mathrm{g} / \mathrm{L}$. MCPP was removed to below detection limit in a simple treatment line where anaerobic groundwater was aerated and subsequently filtrated by primary and secondary rapid sand filters. Water quality parameters were measured throughout the waterworks, and they behaved as designed for. MCPP was removed in secondary rapid sand filters - removal was greatest in the sand filters in the filter line with the highest contact time (63 minutes). In these secondary sand filters, MCPP concentration decreased from $0.037 \mu \mathrm{g} / \mathrm{L}$ to below the detection limit of $0.01 \mu \mathrm{g} / \mathrm{L}$. MCPP was removed continuously at different filter depths $(0.80 \mathrm{~m})$.

Microcosms were set up with filter sand, water and ${ }^{14} \mathrm{C}$-labelled MCPP at an initial concentration of $0.2 \mu \mathrm{g} / \mathrm{L}$. After 24 hours, 79-86\% of the initial concentration of MCPP was removed. Sorption removed 11-15\%, while the remaining part was removed by microbial processes, leading to a complete mineralisation of $13-18 \%$. Microbial removal in the filter sand was similar at different depths of the rapid sand filter, while the amount of MCPP which adsorbed to the filter sand after 48 hours decreased with depth from $21 \%$ of the initial MCPP in the top layer to $7 \%$ in the bottom layer.

It was concluded that MCPP was removed in secondary rapid sand filters at Kerteminde Waterworks, to which both adsorption and microbial degradation contributed.

Keywords: Pesticides; MCPP; removal; waterworks; rapid sand filter; groundwater

\section{Introduction}

Groundwater is used as a source of drinking water all over the world (IWA, 2012). Concentrations of natural and anthropogenic inorganic and organic compounds, such as iron (II), manganese (II), ammonium, arsenic and pesticides, 
Hedegaard et al., 2014. Science of the Total Environment (2014), pp. 257-264. http://dx.doi.org/10.1016/j.scitotenv.2014.08.052

may exceed drinking water guidelines (European Parliament and Council, 1998) in abstracted groundwater which calls for treatment before distributing to consumers.

Pesticides are frequently detected in groundwater abstraction wells all over Europe (EEA, 2013). However, the concentration of pesticides in drinking water and groundwater should not exceed $0.1 \mu \mathrm{g} / \mathrm{L}$ for a single compound, or $0.5 \mu \mathrm{g} / \mathrm{L}$ for the sum of all pesticides (European Parliament and Council, 2006). Pesticides can be removed in drinking water treatment systems by applying advanced technologies such as advanced oxidation (e.g. Suty et al., 2004) and granular activated carbon filtration (GAC) (e.g. Heijman et al., 2002). However, the cost-effectiveness and environmental sustainability of these processes still remain uncertain.

In Denmark, water treatment is generally simple and consists of the aeration of anaerobic groundwater. Aeration is followed by filtration in rapid sand filters designed for a contact time of between 7.5 and 20 minutes. No disinfection is included in the treatment process (Winter et al., 2003). The purpose of aeration is to add oxygen (to a concentration of $8-10 \mathrm{mg} / \mathrm{L}$ ) to the anaerobic inlet water, while volatile compounds such as methane and hydrogen sulphide are stripped off. Increased oxygen concentrations are necessary for the subsequent removal of iron (II), manganese (II) and ammonium.

Rapid sand filters, which are biological filters, are used in drinking water treatment plants globally (Rittmann et al., 2012; Zearley and Summers, 2012; Mouchet, 1992). They constitute a highly complex system of several simultaneous removal mechanisms whereby iron (II) and manganese (II) are removed by physiochemical and biological oxidation processes and precipitation (Mouchet, 1992; Tekerlekopoulou et al., 2013), while ammonium is oxidised biologically in the nitrification process into nitrite and then nitrate (Lytle et al., 2007). The nature and interactions of these processes are not yet understood fully, but it is known that they depend on water quality, the environment and operating conditions (Tekerlekopoulou et al., 2013).

Besides removing inorganic components, different investigations have shown that biological filters can remove organic chemicals such as methyl tert-butyl ether (MTBE) (Arvin et al., 2004), 2-methylisoborneol (MIB) and geosmin (Ho et al., 2007). Though lab-scale studies have shown a biological removal potential of pharmaceuticals and pesticides (Zearley and Summers, 2012; Hedegaard and Albrechtsen, 2014), it is still uncertain whether there is a similar removal potential in full-scale rapid sand filters and the biological chemical processes involved remain unknown (Benner et al., 2013).

In groundwater some of the most frequently detected pesticides are phenoxy acids, including mecoprop (MCPP), which have been used extensively as herbicides in agriculture (Buss et al., 2006). MCPP is still used in some European countries, i.e. France, Italy and Austria (EU Pesticide Database, 2013), but its use has been restricted in Denmark (The Danish Ministry of the Environment, 2013; GEUS, 
2012). However, in Denmark, MCPP was detected in $4.2 \%$ of groundwater samples in the period 1990-2012, and the guideline value of $0.1 \mu \mathrm{g} / \mathrm{L}$ was exceeded in $1.1 \%$ (GEUS, 2013). Usually when guideline is exceeded the normal practice is to close or dilute water from contaminated abstraction wells.

The water treatment at Kerteminde Waterworks, Denmark, consists of the same simple treatment line as other waterworks in Denmark. MCPP contamination has been detected below the guideline value of $0.1 \mu \mathrm{g} / \mathrm{L}$ in abstracted anaerobic groundwater for more than nine years (Figure 1) (Jupiter, 2013), and it has been observed that the herbicide was removed during the treatment (Ferguson et al., 2009). However, it is not known where in the treatment line MCPP was removed, or which mechanisms governed the removal. These questions cannot be answered based on the international literature, so the purpose of this investigation is to:

- Investigate where in the waterworks treatment line MCPP was removed from the water phase.

- Investigate which mechanisms were responsible for the removal of MCPP.

- Investigate whether compounds which the waterworks was designed to remove were actually removed from the water as expected.



Figure 1. MCPP concentrations at Kerteminde Waterworks from the first time MCPP was detected in effluent water up to the investigations, measured in abstraction wells (well number 137.274, 137.439, $137.511,137.610,137.818,137.913,137.914,137.971)$ and in effluent water taken from the waterworks (Jupiter, 2013).

\section{Materials and methods}

\subsection{Investigations at Kerteminde Waterworks}

Kerteminde Waterworks, Denmark, is a typical Danish municipal groundwaterbased waterworks operating a simple treatment line (Figure 2). The waterworks was expanded in 1979, and as a result it now has two parallel filter lines. In the treatment 
line anaerobic groundwater is aerated by diffused air aerators, and filtrated in three parallel primary rapid sand filters. Afterwards, the water is filtrated in parallel secondary sand filters - with a distribution of approximately $20 \%$ of the water to four filters in Filter line 1, which are part of the original waterworks, and $80 \%$ to two parallel filters in Filter line 2, which was added in 1979. Filter characteristics are described in Table 1 . The water is finally stored in clean water tanks before being distributed to consumers. No disinfection is included in the treatment process. The water quality of the groundwater is characterised by reduced conditions in the aquifer, expressed by low nitrate concentrations, for instance (Table 2).

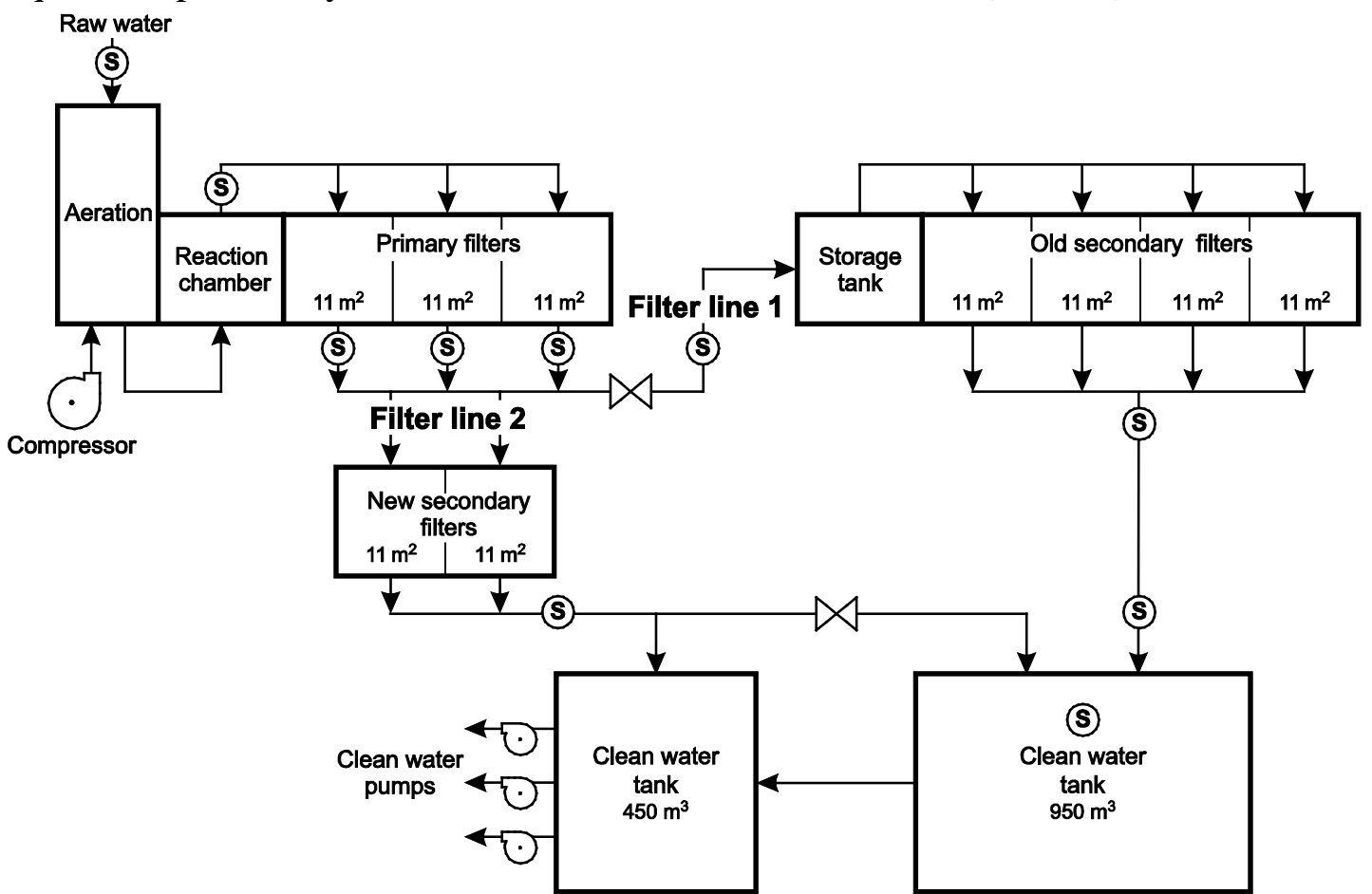

Figure 2. Schematic of the treatment system at Kerteminde Waterworks. Water was distributed with approximately $20 \%$ to Filter line 1 ( $\mathrm{t}_{\text {contact }}=63$ minutes), and $80 \%$ to Filter line 2 ( $\mathrm{t}_{\text {contact }}=8$ minutes).

During the investigations Kerteminde Waterworks distributed about 600,000 $\mathrm{m}^{3}$ of water per year and received raw water from eight groundwater abstraction wells, seven of which were contaminated with varying concentrations of phenoxy acids, especially MCPP (below $0.01 \mu \mathrm{g} / \mathrm{L}$ to $0.080 \mu \mathrm{g} / \mathrm{L}$, Figure 1 ). The waterworks was operated 24 hours a day, with flow varying according to consumption. The inlet concentration of MCPP depended on the combination of abstraction wells and could be anything up to $0.08 \mu \mathrm{g} / \mathrm{L}$. The investigations in this paper were carried out in two steps, as described in the following. 


\begin{tabular}{|c|c|c|c|c|}
\hline \multirow[b]{3}{*}{ Water flow (Q) } & \multirow[b]{3}{*}{$\mathrm{m}^{3} /$ day } & \multirow[t]{2}{*}{ Primary filter } & \multicolumn{2}{|c|}{ Secondary filter } \\
\hline & & & Filter line 1 & Filter line 2 \\
\hline & & 1600 & 320 & 1280 \\
\hline Number of filters & no. & 3 & 4 & 2 \\
\hline Backwashes & no./week & 7 & 4 & 4 \\
\hline Area per filter (A) & $\mathrm{m}^{2}$ & 11 & 11 & 11 \\
\hline Depth (L) & $\mathrm{m}$ & 1.00 & 0.80 & 0.80 \\
\hline Composition of filter & & $\begin{array}{l}\text { Anthracite and } \\
\text { quartz }\end{array}$ & Quartz sand & Quartz sand \\
\hline Grain size & & $\begin{array}{c}0-0.40 \mathrm{~m}: 3.5-7 \mathrm{~mm} \\
0.40-1.00 \mathrm{~m}: 3-5 \mathrm{~mm}\end{array}$ & 0-0.80m: $1-2 \mathrm{~mm}$ & $0-0.80 \mathrm{~m}: 1-2 \mathrm{~mm}$ \\
\hline Superficial flow velocity (U) ${ }^{*}$ & $\mathrm{~m} /$ hour & 2.0 & 0.3 & 2.4 \\
\hline 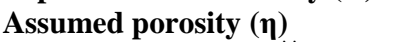 & $\%$ & 40 & 40 & 40 \\
\hline Filter velocity $\left(\mathbf{U}_{\text {pore }}\right)^{* * *}$ & $\mathrm{~m} /$ hour & 5.1 & 0.8 & 6.1 \\
\hline Contact time $\left(\mathbf{T}_{\mathrm{h}}\right)^{* * * *}$ & $\min$ & 12 & 63 & 8 \\
\hline \multicolumn{5}{|l|}{$* \mathrm{U}=\mathrm{Q} / \mathrm{A}$} \\
\hline$* *$ Upore $=\mathrm{U} / \eta$ & & & & \\
\hline *** Th = L/ Upore & & & & \\
\hline
\end{tabular}

MCPP removal at Kerteminde Waterworks. It was investigated where in the treatment line MCPP was removed. Water quality parameters were measured throughout the waterworks in Filter line 1 (Figure 2), where the secondary rapid filters had a contact time of 63 minutes (Table 1).

MCPP removal mechanisms at Kerteminde Waterworks. The removal of MCPP was investigated throughout Kerteminde Waterworks in Filter line 2, by focusing on the secondary rapid sand filters with a contact time of 8 minutes (Table 1). Reactions in the filter sand were investigated at different depths, and two laboratory experiments were carried out to investigate a) the microbial degradation potential of MCPP and b) the sorption capacity of the filter sand.

\begin{tabular}{lccc}
\hline \multicolumn{3}{l}{ Table 2. Water quality parameters in the inlet for the waterworks and in the big clean } \\
water tank. & Unit & Inlet water & Clean water tank \\
\hline Parameter & & 7.5 & 7.6 \\
pH & $\mathrm{ms} / \mathrm{m}$ & 100 & 100 \\
Conductivity & ${ }^{\circ} \mathrm{dH}^{*}$ & 23.4 & 24.3 \\
Hardness & $\mathrm{FTU}$ & 70 & 0.15 \\
Turbidity & $\mathrm{mg} / \mathrm{L}$ & 4.1 & 3.1 \\
NVOC & $\mathrm{mg} / \mathrm{L}$ & 0.80 & 10.4 \\
Oxygen & $\mathrm{mg} / \mathrm{L}$ & $<0.50$ & 1.5 \\
Nitrate-NO & $\mathrm{mg} / \mathrm{L}$ & 0.11 & $<0.005$ \\
Nitrite-NO & $\mathrm{mg} / \mathrm{L}$ & 0.59 & $<0.0060$ \\
Ammonium-NH & $\mathrm{m}$ ( & 0.23 & $<0.05$ \\
Manganese (II) & $\mathrm{mg} / \mathrm{L}$ & 4.6 & 0.018 \\
Iron (II) & $\mathrm{mg} / \mathrm{L}$ & 170 & 170 \\
Sulphate & $\mathrm{mg} / \mathrm{L}$ & 140 & 150 \\
Calcium & $\mathrm{mg} / \mathrm{L}$ & 15 & 16 \\
Magnesium & $\mathrm{mg} / \mathrm{L}$ & 3.7 & 3.8 \\
Potassium & $\mathrm{mg} / \mathrm{L}$ & 49 & 49 \\
Sodium & $\mathrm{mg} / \mathrm{L}$ & 0.36 & 0.28 \\
Fluoride & $\mathrm{mg} / \mathrm{L}$ & 357 & 345 \\
Bicarbonate & $\mathrm{mg} / \mathrm{L}$ & 0.11 & $<0.005$ \\
Total-Phosphorous-(P) & $\mu \mathrm{L} / \mathrm{L}$ & 0.037 & $<0.010$ \\
MCPP &
\end{tabular}

*German hardness degree: $1^{\circ} \mathrm{dH}=17.8 \mathrm{mg} / \mathrm{L} \mathrm{CaCO} 3$ 
Hedegaard et al., 2014. Science of the Total Environment (2014), pp. 257-264.

http://dx.doi.org/10.1016/j.scitotenv.2014.08.052

\subsection{Water samples}

Water samples were collected throughout the treatment line at Kerteminde Waterworks and then analysed for water quality parameters by the certified company EUROFINS A/S. Water samples were collected before aeration, after the reaction chamber and after each of the three primary filters in mixed water from the secondary filters in Filter line 1, mixed water from the secondary filters in Filter line 2 , inside the large clean water tank and from the inlet to the small clean water tank (Figure 2).

Water samples were collected from different depths down through the secondary sand filters of Filter line 2 ( $\mathrm{t}_{\text {contact }}=8$ minutes). Samples were collected at least $0.5 \mathrm{~m}$ horizontal from the wall of the rapid sand filter, with a sterile stainless steel pipe (length: $150 \mathrm{~cm}$, outside diameter $10 \mathrm{~mm}$, inner diameter $7 \mathrm{~mm}$ ) which had an intake screen on $2 \mathrm{~cm}$ on the tip. The water was drawn through the pipe in a silicone tube (inner diameter $10 \mathrm{~mm}$ ) with a peristaltic pump at a flow rate of $300 \mathrm{~mL} / \mathrm{min}$. Thereby only a small fraction of the available water in the sampling depth interval was collected. Before water samples were collected, the sampling device was flushed with water for 5 minutes - equating to 12 water volumes.

Mixed effluent water from the secondary filters in Filter line 1 was used as test water for the microbial degradation and sorption experiments. The water was sterilefiltrated $(0.2 \mu \mathrm{m}$ filters $)$ and stored below $10^{\circ} \mathrm{C}$ in the dark in sterile $5 \mathrm{~L}$ PYREX oven heated bottles (used within 24 hours).

\subsection{Collection of filter sand}

Filter sand was collected by a sterile stainless steel sampler (inner diameter $6 \mathrm{~cm}$ ) with a closure in the bottom of polyethylene. The sampler was installed inside a sterile stainless steel casing, which was pressed down into the filter sand to the sampling depths, in order to allow for the withdrawal of samples which were then transferred to sterile glass jars and transported to the laboratory in cooling bags. The filter material was stored at $10^{\circ} \mathrm{C}$ until the microcosms were set up (within 24 hours).

\subsection{Chemicals}

The experiments were carried out with [ring- ${ }^{14} \mathrm{C}$ ]-MCPP isotops (Izotop, Institute of Isotopes Co., Ltd., Hungary) with a radiochemical purity of $>95 \%$ and a specific activity of $23 \mathrm{mCi} / \mathrm{mmol}$ according to the manufactor. $\left[{ }^{14} \mathrm{C}\right]-\mathrm{MCPP}$ was diluted in MilliQ water.

\subsection{Microbial degradation}

Microcosms were set up by applying 80 g wet filter sand (dry weight $79.17 \pm 0.13$ g) and $80 \mathrm{~mL}$ test water to $300 \mathrm{~mL}$ serum bottles. Abiotic controls were microcosms to which sodium azide was added to a final concentration of $2 \mathrm{~g} / \mathrm{L}$. They were set up the same day as filter sand was collected at the waterworks - the day before the experiment took place, in order to achieve the efficient inhibition of microbial 
activity. Microcosms and abiotic controls were set up in triplicate for each filter depth. Additionally, controls with water only were set-up with unsterilised test water, but without filter sand, to investigate the degradation potential of the test water. All microcosms and controls were closed with Teflon caps and aluminum lids and incubated in dark.

Within 24 hours after the filter sand was collected at Kerteminde Waterworks, the experiment was started by adding ${ }^{14} \mathrm{C}-\mathrm{MCPP}$ to an initial concentration of $0.2 \mu \mathrm{g} / \mathrm{L}$. Water samples were collected from the microcosms frequently during the first six hours, and once after 24 hours. Water samples of $5 \mathrm{~mL}$ were collected by a sterile syringe through the Teflon cap and filtered (0.2 $\mu \mathrm{m}$ PTFE, Advancetec/MFS $13 \mathrm{HP})$ into $20 \mathrm{~mL}$ vials. The extracted water volume from the microcosms was replaced with sterile air. A double-vial system was set up to strip off ${ }^{14} \mathrm{CO}_{2}$ produced from the water sample, by adding $37 \% \mathrm{HCl}$ and then catching ${ }^{14} \mathrm{CO}_{2}$ in a base $(1 \mathrm{~mL} 2 \mathrm{M}$ $\mathrm{NaOH})$ in an inner vial $(6 \mathrm{~mL})$ (Janniche et al., 2010). The ${ }^{14} \mathrm{C}$-activity of the water sample and ${ }^{14} \mathrm{CO}_{2}$ was subsequently quantified.

\subsection{Sorption}

Serum bottles $(50 \mathrm{~mL})$ were set up with $20 \mathrm{~g}$ wet filter sand (dry weight $19.79 \pm$ $0.03 \mathrm{~g}$ ) and $10 \mathrm{~mL}$ sodium azide solution at a concentration of $4 \mathrm{~g} / \mathrm{L}$, to inhibit microbial activity in the filter sand, the same day filter sand was collected. Three replicas were made with filter sand from each of the four layers, and the bottles were closed with Teflon caps and aluminium lids and then stored overnight at $10^{\circ} \mathrm{C}$ in the darkness.

The next morning, $10 \mathrm{~mL}{ }^{14} \mathrm{C}-\mathrm{MCPP}$ was added to reach an initial concentration of $0.2 \mu \mathrm{g} / \mathrm{L}$. The bottles were then incubated in a $10^{\circ} \mathrm{C}$ orbital incubator $(1,400$ rotations/day) for 48 hours, to reach MCPP equilibrium between the filter sand and the water. Samples of $5 \mathrm{~mL}$ were extracted from the water phase and filtered $(0.2 \mu \mathrm{m}$ PTFE, Advancetec/MFS $13 \mathrm{HP}$ ) into $20 \mathrm{~mL}$ vials. The extracted water volume was replaced with sterile air. Base traps were made in the $20 \mathrm{~mL}$ vials, as described under "2.5 Microbial degradation”, while data were analysed assuming a linear isotherm:

$$
K_{d}={ }^{14} C_{s} /{ }^{14} C_{w}
$$

where ${ }^{14} \mathrm{C}_{\mathrm{s}}$ is the amount of MCPP adsorbed into the filter sand and ${ }^{14} \mathrm{C}_{\mathrm{w}}$ is the amount of MCPP in the water phase, given in $\mathrm{L} / \mathrm{kg}$.

\subsection{Measurements of ${ }^{14} \mathrm{C}$-activity}

Base traps were stored for at least two days to assure that all ${ }^{14} \mathrm{CO}_{2}$ was stripped off and caught by the base in the $6 \mathrm{~mL}$ vials. A scintillation liquid (Optiphase HiSafe 3 , Wallac) was added to the $20 \mathrm{~mL}$ and $6 \mathrm{~mL}$ vials. The vials were kept for two days in dark after which ${ }^{14} \mathrm{C}$-activity in the samples was quantified by a liquid scintillation analyser (WinSpectralTM, 1414 Liquid Scintillation Counter). 
Hedegaard et al., 2014. Science of the Total Environment (2014), pp. 257-264. http://dx.doi.org/10.1016/j.scitotenv.2014.08.052

\section{Results and discussion}

\subsection{Waterworks}

Water quality parameters were measured in inlet water and effluent water of the waterworks (Table 2). The raw water contained high concentrations of iron (II) and manganese (II), and MCPP had been continuously detected in raw water for nine years (Figure 1).

Total water flow through the waterworks was approximately $1,600 \mathrm{~m}^{3} /$ day, split between $320 \mathrm{~m}^{3} /$ day for Filter line 1 and $1,280 \mathrm{~m}^{3} /$ day for Filter line 2 . The sand in the secondary rapid sand filters in Filter line 2 was very homogeneous over all depths, and over $90 \%$ of the sand had a diameter of $1-2 \mathrm{~mm}$ with an average diameter of $1.5 \mathrm{~mm}$ (Table 1). With an assumed porosity of $40 \%$ this gave an average filter pore velocity of $0.8 \mathrm{~m} /$ hour in Filter line 1, resulting in a contact time of 63 minutes, while in Filter line 2 the filter pore velocity was $6.1 \mathrm{~m} /$ hour and the contact time was 8 minutes (Table 1). Consequently, contact time in the secondary sand filters in Filter line 2 was within the normal range of between 7.5 and 20 minutes for rapid sand filters (Winter et al., 2003), while the contact time in Filter line 1 was substantially longer.

The amount of total organic carbon (TOC) in the filter material was very low at all filter depths, at approximately $1 \mathrm{mg} / \mathrm{g}$ of the dry filter sand (Figure 3). The coating by iron and manganese oxides decreased in line with filter depth. Hence, manganese (II) decreased from 5.2 to $4.4 \mathrm{mg} / \mathrm{g}$ of the dry filter sand, and iron (II) decreased from 8.5 to $6.1 \mathrm{mg} / \mathrm{g}$ of the dry filter sand (Figure 3).



Figure 3. The average and standard deviations of the amount of manganese, iron and TOC ( $\geq$ three replicates) in the secondary sand filters of Filter line 2 ( $\mathrm{t}_{\text {contact }}=8$ minutes).

\subsection{Water quality parameters throughout Kerteminde Waterworks}

Concentrations of different natural groundwater contaminants were measured throughout Kerteminde Waterworks in Filter line 2, to investigate whether 
compounds which the waterworks was designed to remove were actually removed from the water as expected (Figure 4).

Oxygen concentration increased to $10.3 \mathrm{mg} / \mathrm{L}$ during aeration and did not decrease to less than $9.9 \mathrm{mg} / \mathrm{L}$ throughout the subsequent treatment process (Figure 4).

Iron (II) concentration in the water phase decreased from $4.4 \mathrm{mg} / \mathrm{L}$ to $3.3 \mathrm{mg} / \mathrm{L}$ during aeration and in the subsequent reaction chamber, but it was removed primarily in the primary filters, where the concentration decreased from $3.3 \mathrm{mg} / \mathrm{L}$ to 0.22 $\mathrm{mg} / \mathrm{L}$. In the secondary filters, iron (II) decreased to below the detection limit (Figure 4).

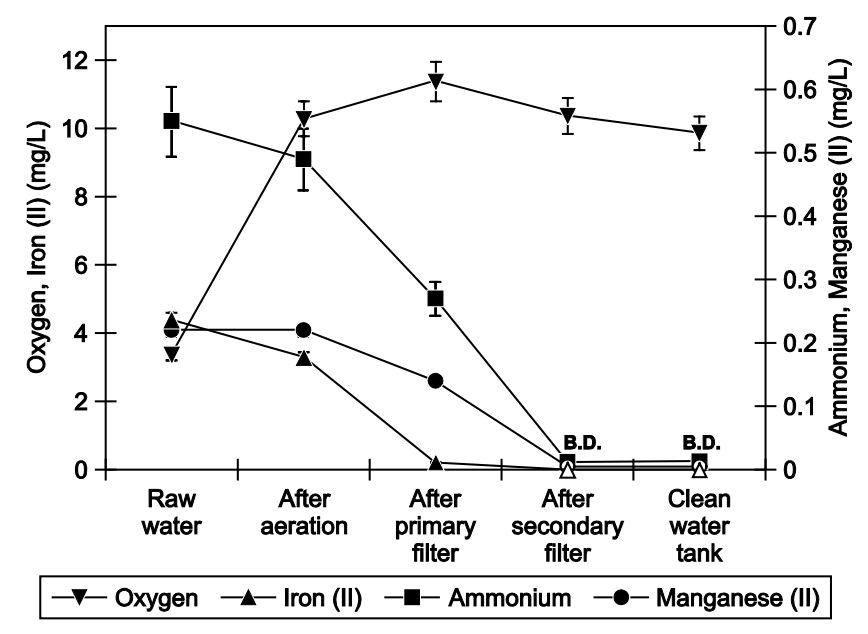

Figure 4. Oxygen, iron (II), ammonium and manganese (II) concentrations in the water phase at Kerteminde Waterworks through Filter line 2 ( $\mathrm{t}_{\text {contact }}=8$ minutes). B.D. marks measuring points below the detection limit, which are illustrated by open markers.

Aeration did not influence the concentration of manganese (II) at $0.22 \mathrm{mg} / \mathrm{L}$. Manganese (II) was removed in both the primary and secondary rapid sand filters, albeit mainly in the secondary filters, where the concentration decreased from 0.14 $\mathrm{mg} / \mathrm{L}$ to below the detection limit (Figure 4).

Ammonium concentration decreased from $0.55 \mathrm{mg} / \mathrm{L}$ to $0.49 \mathrm{mg} / \mathrm{L}$ during aeration. In the primary rapid sand filters ammonium concentration decreased to 0.27 $\mathrm{mg} / \mathrm{L}$, while it decreased to $0.012 \mathrm{mg} / \mathrm{L}$ in the secondary rapid sand filters (Figure 4).

Hence, the investigations revealed that iron (II) was removed principally in the primary filter. Ammonium concentrations decreased in the primary and secondary filters, while manganese (II) was removed mainly in the secondary filter. Iron and ammonium are known to affect manganese oxidation, which explains why manganese was oxidised mostly after the iron (II) and ammonium concentrations decreased (Tekerlekopoulou, 2013; Mouchet, 1992). 


\subsection{MCPP concentrations throughout Kerteminde Waterworks}

MCPP concentration was affected by neither the aeration process nor the primary

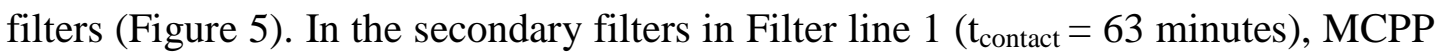
concentration decreased from $0.037 \mu \mathrm{g} / \mathrm{L}$ to below the detection limit $(0.010 \mu \mathrm{g} / \mathrm{L})$, and in Filter line 2 ( $\mathrm{t}_{\text {contact }}=8$ minutes) it decreased from $0.046 \mu \mathrm{g} / \mathrm{L}$ to $0.025 \mu \mathrm{g} / \mathrm{L}$. Hence, most MCPP was removed in the secondary filter in Filter line 1 ( $\mathrm{t}_{\text {contact }}=63$ minutes). However, when water from the two filter lines was mixed in the clean water tanks, MCPP was diluted to below the detection limit.



Figure 5. MCPP concentrations in the water phase at Kerteminde Waterworks through Filter line 1 $\left(\mathrm{t}_{\text {contact }}=63\right.$ minutes $)$ and Filter line $2\left(\mathrm{t}_{\text {contact }}=8\right.$ minutes $)$. B.D. marks measuring points below the detection limit, which are illustrated by open markers.

\subsection{Depth profiles of water quality in the secondary rapid sand filter}

As MCPP was removed in the secondary rapid sand filters, water quality parameters were measured over different depths in the secondary sand filters in Filter line 2 ( $\mathrm{t}_{\text {contact }}=8$ minutes), in order to investigate the depth profiles (Figure 6$)$. The removal of iron (II), manganese (II) and ammonium was stratified over different depths. Iron (II) concentrations decreased mainly in the top $30 \mathrm{~cm}$, while manganese (II) also dissipated quickly in the top layers of the secondary filter and decreased to below the detection limit in the upper $70 \mathrm{~cm}$. Ammonium was removed continuously in the upper $70 \mathrm{~cm}$ of the filter, while in the lower part this removal decreased. Hence, inorganic compounds were removed by the filter, as expected. Contrary to the stratified removal of inorganic compounds, MCPP was removed continuously in all filter sand layers (Figure 6). 


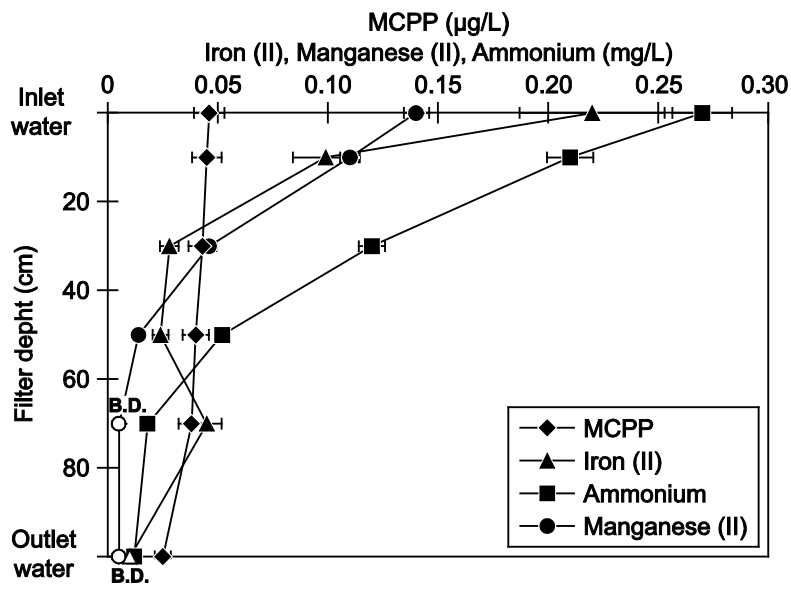

Figure 6. Profiles of iron (II), ammonium, manganese (II) and MCPP concentrations at different filter depths for secondary rapid sand filters in the Kerteminde Waterworks Filter line $2\left(\mathrm{t}_{\text {contact }}=8\right.$ minutes). B.D. marks measuring points below the detection limit, which are illustrated by open markers.

\subsection{Removal of MCPP by microbial degradation}

It was investigated whether the removal of MCPP in the rapid sand filter was governed by abiotic or microbial removal mechanisms. The microbial degradation potential of the different layers in the filter sand was investigated in microcosms. After 24 hours, 79-86\% of the MCPP was removed by filter sand at all depths (Figure 7a). According to removal in the abiotic controls, sorption processes were responsible for $11-15 \%$ of MCPP dissipation over a 24-hour period (Figure 7a). After 24 hours approximately 70\% more MCPP was removed in the active microbial microcosms than in the abiotic controls, so the filter sand showed an evident microbial degradation potential. The removal of MCPP was in fact rapid concentration decreased by approximately $40 \%$ during the first three hours.

Microbial degradation in the different filter sand layers did not differ substantially (Figure 7a), which was consistent with changes in MCPP concentration over different depth in the filter, which showed an equal removal of MCPP in all filter layers (Figure 6). In samples from all filter depths, MCPP was partially mineralised (Figure $7 \mathrm{~b}$ ). After 24 hours, $12.5-17.5 \%$ of the ${ }^{14} \mathrm{C}$ in the microcosms was recovered as ${ }^{14} \mathrm{CO}_{2}$ (in contrast to abiotic controls, where $2 \%$ was detected). Hence, part of the observed MCPP removal led to complete microbial degradation of the pesticide.

MCPP was not removed in the controls with water only (Figure 7a), and mineralisation in this case corresponded to what was detected in the abiotic controls (Figure 7b). Hence, there was no removal potential of the water, and removal in the microcosms must have been caused by processes in the filter sand. 
Hedegaard et al., 2014. Science of the Total Environment (2014), pp. 257-264.

http://dx.doi.org/10.1016/j.scitotenv.2014.08.052
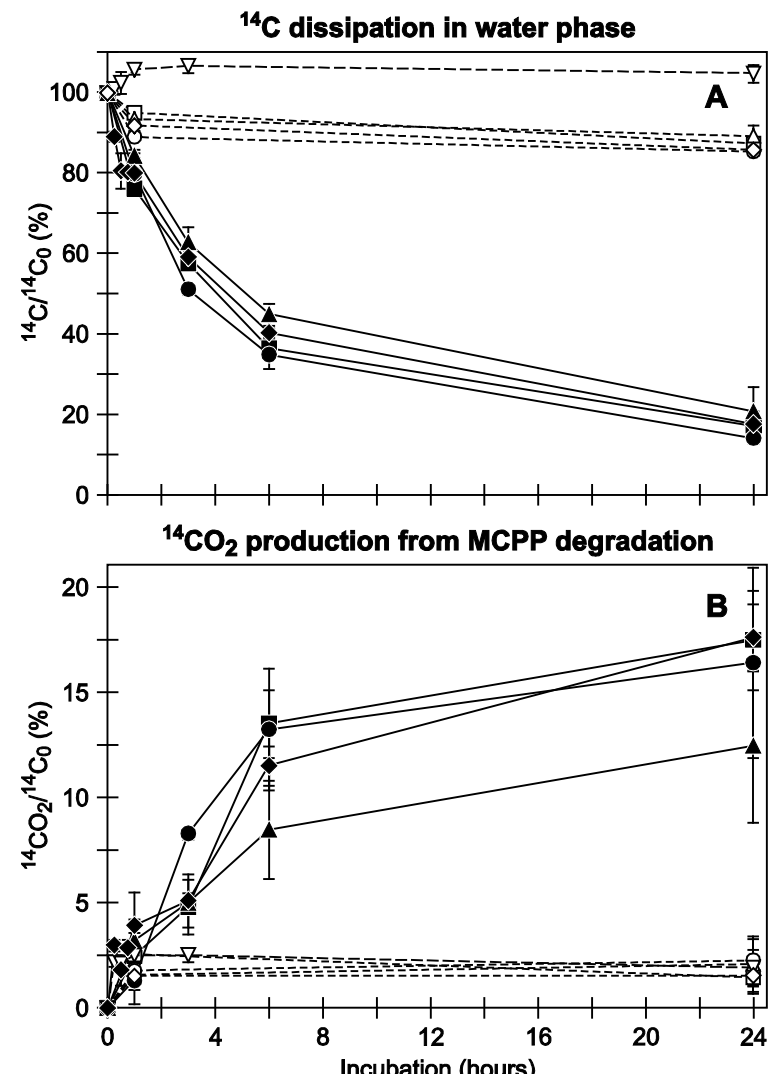

$$
\begin{array}{rl|}
-\checkmark-0-20 \mathrm{~cm} & -\checkmark--0-20 \mathrm{~cm} \text { abiotic control } \\
-\square-20-40 \mathrm{~cm} & --\square-20-40 \mathrm{~cm} \text { abiotic control } \\
--40-60 \mathrm{~cm} & --\triangle--40-60 \mathrm{~cm} \text { abiotic control } \\
--60-80 \mathrm{~cm} & ---60-80 \mathrm{~cm} \text { abiotic control } \\
& -\nabla-\text { Water W/O filter sand }
\end{array}
$$

Figure 7. Microbial degradation of MCPP in microcosms (triplicates) and abiotic controls with filter sand from four filter depths. Mean values and standard deviations are shown for a) MCPP concentration in the water phase $\left({ }^{14} \mathrm{C} /{ }^{14} \mathrm{C}_{0}\right)$ and b) ${ }^{14} \mathrm{CO}_{2}$ production as a result of MCPP degradation in the water phase $\left({ }^{14} \mathrm{CO}_{2} /{ }^{14} \mathrm{C}_{0}\right)$. Water W/O filter sand shows MCPP removal in the control with water only.

\subsection{Removal by sorption}

In the top layer of the secondary filter, 21\% of the initial MCPP adsorbed onto the filter sand within 48 hours (Figure 8). Sorption capacity decreased in line with filter depth, and in the lower layer only $7 \%$ of the initial MCPP was removed by adsorption. Assuming a linear isotherm, this corresponds to a decrease in the distribution constant $\mathrm{K}_{\mathrm{d}}$, from $0.27 \mathrm{~L} / \mathrm{kg}$ to $0.08 \mathrm{~L} / \mathrm{kg}$, which is higher than on quartz from aquifer material where sorption was undetectable - less than $1 \%$ (Clausen et al., 2001). 


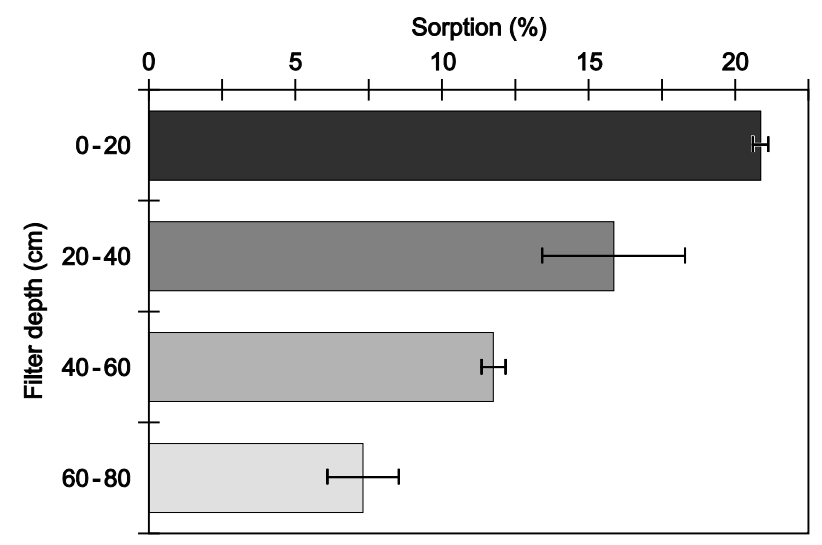

Figure 8. Sorption of MCPP onto filter sand after 48 hours of abiotic sorption investigations (triplicates) with filter sand from four filter depths. The mean value and standard deviation show how large a fraction (\%) of the initial MCPP has been removed by sorption $\left(\left({ }^{14} \mathrm{C}_{0}-{ }^{14} \mathrm{C}_{\mathrm{aq}}\right) \cdot 100 \% /{ }^{14} \mathrm{C}_{0}\right)$.

\section{Perspectives}

The concentration of different compounds which the waterworks was designed to remove, were removed through the treatment line as expected. Hence, the water treatment processes at Kerteminde Waterworks were functioning well and removed unwanted substances. However, the treatment line at Kerteminde Waterworks differed from the normal operation at waterworks in Denmark by having long contact times (63 minutes) in the secondary filters at Filter line 1, which was where the most substantial MCPP removal was observed. MCPP was removed in secondary rapid sand filters, where several abiotic and biological processes were constantly removing natural inorganic and organic contaminants, namely iron (II), manganese (II), ammonium, methane, hydrogen sulfide and natural organic matter (NOM). It should be noted that all of these processes may interact, and as such they constitute a very reactive environment for the degradation of different organic compounds, including MCPP.

Contact time for the water in Filter line 1 was eight times longer (63 minutes) than in Filter line 2 (8 minutes) (Table 2). Despite the short contact time in Filter line 2, the secondary rapid sand filters removed more than 50\% of the inlet MCPP, and the removal of MCPP was thus was very efficient. The complete removal in Filter line 1 might simply be due to a longer reaction time in the filter; otherwise, the longer contact time could cause greater biomass and thereby the increased microbial degradation of MCPP in the filter. Other research has also indicated that longer contact time has a positive effect on the removal of micro pollutants in rapid sand filters (Hedegaard and Albrechtsen, 2014; Zuehlke et al., 2007).

Filter sand has a characteristic mineral coating due to the precipitation of metal oxides during water treatment. Though iron (II) and manganese (II) were removed from the water phase in the upper layers of the secondary rapid sand filter (Figure 6), 
Hedegaard et al., 2014. Science of the Total Environment (2014), pp. 257-264.

http://dx.doi.org/10.1016/j.scitotenv.2014.08.052

their oxides were present at all filter depths, probably due to mixing during backwashing (Figure 3). However, the concentration of metal oxides was stratified and decreased according to depth. At a neutral $\mathrm{pH}$, MCPP adsorption onto minerals such as quartz and calcite is undetectable (Clausen et al., 2001), while MCPP can adsorb onto iron oxides (Clausen and Fabricius, 2001). Hence, the observed abiotic removal of MCPP could be related to precipitated iron oxides in the rapid sand filters. However, MCPP was not removed in the primary filters, where most iron oxides precipitated (Figure 4 and 6), so adsorption onto iron oxides was therefore unlikely to be the governing removal process. The adsorption of other pesticides into activated carbon could be enhanced by a manganese oxide coating (Cui et al., 2012). Since manganese oxides were present at all filter depths, the adsorption of MCPP onto manganese oxides could explain why MCPP was removed continuously throughout the filter. The decreasing concentration of manganese oxides according to filter depth could explain why the distribution constant of MCPP as a measure of sorption capacity decreased from $0.27 \mathrm{~cm}^{3} / \mathrm{g}$ to $0.08 \mathrm{~cm}^{3} / \mathrm{g}$. The removal of MCPP by sorption might be influenced by backwashing the filters, which occurred four times a week for the secondary sand filters (Table 1). Backwashing removes some of the mineral coating on the filters, and it might thereby remove some of the adsorbed MCPP. However, any loss of mineral coating could also decrease sorption capacity, if MCPP adsorbed onto precipitated oxides.

Since MCPP was removed completely in Filter line 1 ( $\mathrm{t}_{\text {contact }}=63$ minutes), adsorption cannot be the sole removal mechanism; in this case, microbial degradation also contributed to the removal of MCPP. This was also emphasised by the microcosm investigations, which showed a substantial amount of microbial degradation potential in the filter sand (Figure 7). MCPP removal might be caused by an interaction between adsorption and microbial degradation, where MCPP initially adsorbs onto the mineral coatings on sand grains, from where it is accessible to micro-organisms.

Filter sand from Kerteminde Waterworks showed substantial potential for the aerobic biodegradation and mineralisation of MCPP at sub $\mu \mathrm{g} / \mathrm{L}$ concentrations. This corresponds to previous observations of aerobic biodegradation of MCPP with aquifer materials (Janniche et al., 2010; Toräng and Albrechtsen, 2003). However, an adaptation phase of more than 16 days is required before MCPP degradation is initiated in aquifer material (Agertved et al., 1992; Tuxen et al., 2000; Janniche et al., 2010). Filter sand that has not previously been exposed to pesticides is able to remove pesticides without an adaptation phase (Hedegaard and Albrechtsen, 2014) and in the current laboratory experiments degradation of MCPP was also initiated immediately (Figure 7). However, the secondary filters at Kerteminde Waterworks had been exposed to concentrations of MCPP for at least nine years prior to these investigations (Figure 1). The concentration of MCPP in waterworks effluent water and in abstraction wells followed the same pattern until approximately 2000, where it 
decreased rapidly in the effluent water over two years compared to the decrease in the abstraction wells (Figure 1). It was therefore evident that the processes at Kerteminde Waterworks were enhanced in this period as far as MCPP removal was concerned. However, it was not possible to determine if the increased MCPP removal was due to an adaptation of the microbial community resulting in microbial degradation of MCPP.

\section{Conclusion}

These investigations have shown that:

- The herbicide MCPP was removed from an inlet concentration of $0.037 \mu \mathrm{g} / \mathrm{L}$ to below the detection limit of $0.010 \mu \mathrm{g} / \mathrm{L}$ out through Kerteminde Waterworks.

- Water treatment processes at the waterworks performed in the same way as comparable waterworks, though contact time in the secondary rapid sand filters in Filter line 1 was long, 63 minutes. Aeration added oxygen to anaerobic groundwater. Iron (II) was removed mainly in the primary filter, which also decreased ammonium concentration. Manganese (II) was removed primarily in the secondary rapid sand filters. Hence, rapid sand filters supported several abiotic and biological processes and included competences for the degradation of different compounds.

- MCPP concentration decreased continuously at different depths in the fullscale secondary filters and decreased mostly (from $0.037 \mu \mathrm{g} / \mathrm{L}$ to below the detection limit $(0.010 \mu \mathrm{g} / \mathrm{L}))$ in the filters in Filter line 1 , where water velocity was low ( $\mathrm{t}_{\text {contact }}=63$ minutes $)$.

- In laboratory investigations, filter sand removed MCPP both by sorption and by microbial degradation. After 24 hours, $79-86 \%$ of MCPP was removed, out of which $11-15 \%$ was removed by abiotic processes, $13-18 \%$ was completely mineralised and the remaining fraction was removed by microbial processes, which did not lead to complete mineralisation within 24 hours.

- Filter sand from different depths showed that the microbial removal of MCPP did not change according to depth, while adsorption decreased in line with the depth of the filter.

The removal of MCPP at Kerteminde Waterworks showed that a full-scale rapid sand filter at a Danish waterworks was able to remove pesticide contamination from drinking water. If sand filters can be used in this respect, it is of substantial commercial interest, since this treatment method is simple and environmentally and economically sustainable (Godskesen et al., 2011). 
Hedegaard et al., 2014. Science of the Total Environment (2014), pp. 257-264.

http://dx.doi.org/10.1016/j.scitotenv.2014.08.052

\section{Acknowledgements}

This research was partially funded and carried out in cooperation with the former Fyns County, Denmark, and the Danish Kerteminde Waterworks, Kerteminde Forsyningen A/S. The authors thank Camilla Ferguson for carrying out the technical report. Ruben Steffensen, Martin Rasmussen and Kenneth Nikolajsen, from Kerteminde Waterworks, and Liselotte Clausen, who was quality consultant on the project, also receive our gratitude for their kindly assistance. We confirm that there are no known conflicts of interest associated with this publication.

\section{References}

Agertved, J., Rügge, K., Barker, J. F., 1992. Transformation of the herbicides MCPP and Atrazine under natural aquifer conditions, Ground Water 30 (4), 500-506.

Arvin, E., Nielsen, L. K., Tully, A. G., Albrechtsen, H.-J., Mosbæk, H., 2004. MTBE removal by biofiltration in a water works, IWA Publishing Company, $2^{\text {nd }}$ IWA Leading-Egde Conference on Water and Wastewater Treatment Technologies, 147-150.

Benner, J., Helbling, D. E., Kohler, H.-P. E., Wittebol, J., Kaiser, E., Prasse, C., Ternes, T. A., Albers, C. N., Aamand, J., Horemans, B., Springael, D., Walravens, E., Boon, N., 2013. Is biological treatment a viable alternative for micropollutant removal in drinking water treatment processes? Water Research 47, 5955-5976.

Buss, S. R., Thrasher, J., Morgan, P., Smith, J. W. N., 2006. A review of mecoprop attenuation in the subsurface, Quarterly Journal of Engineering Geology and Hydrogeology 39, 283-292.

Clausen, L., Fabricius, I., 2001. Atrazine, isoproturon, mecoprop, 2,4-D and bentazone adsorption to iron oxides, Journal of Environmental Quality 30 (3), 858869.

Clausen, L., Fabricius, I., Madsen, L., 2001. Adsorption of pesticides onto Quartz, Calcite, Kaolinite, and $\alpha$-Alumina, Journal of environmental quality 30 (3), 858-869.

Cui, H., Li, Q., Qian, Y., Zhang, Q., Zhai, J., 2012. Preparation and adsorption performance of $\mathrm{MnO} 2 / \mathrm{PAC}$ composite towards aqueous glyphosate, Environmental Technology 33 (17), 2049-2056.

EU Pesticide Database, 2013. Mecoprop, EU pesticide database, European Union. http://ec.europa.eu/sanco_pesticides/public/index.cfm?event=activesubstance.detail (accessed 14.06.13).

EEA, 2013. Pesticides in Groundwater. European Environment Agency. http://www.eea.europa.eu/data-and-maps/indicators/pesticides-in-groundwater (accessed 14.06.13).

European Parliament and Council, 1998. Council Directive 98/83/EC of 3 November 1998 on the quality of water intended for human consumption. 
European Parliament and Council, 2006. Directive 2006/118/EC of the European Parliament and of the Council of 12 December 2006 on the Protection of Groundwater against Pollution and Deterioration.

Ferguson, C., Corfitzen, C. B., Albrechtsen, H.-J., Arvin, E., 2009. Investigation of pesticide removal at Kerteminde Waterworks with a view to optimise water treatment processes (in Danish). DTU Environment, The Technical University of Denmark, Denmark.

GEUS, 2013. Groundwater monitoring 2013 - Groundwater status and development 1989-2012 (in Danish), The Geological Survey of Denmark and Greenland, Ministry of Climate, Energy and Building, Denmark.

Godskesen, B., Zambrano, K. C., Trautner, A., Johansen, N.-B., Thiesson, L., Andersen, L., Clausin-Kaas, J., Neidel, T. L., Rygaard, M., Kløverpris, N. H., Albrechtsen, H.-J., 2011. Life cycle assessment of three water systemsin Copenhagen-a management tool of the future,Water Science and Technology 63 (3), 565-572.

Hedegaard, M. J., Albrechtsen, H.-J., 2014. Microbial pesticide removal in rapid sand filters for drinking water treatment - Potential and kinetics, Water Research 48, 71-81.

Heijman, S. G. J., Siegers, W., Sterk, R., Hopman, R., 2002. Prediction of breakthrough of pesticides in GAC-filters and breakthrough o colour in ionexchange-filters, Water Science and Technology: Water Supply 2 (1), 103-108.

Ho, L., Hoefel, D., Bock, F., Saint, C. P., Newcombe, G., 2007. Biodegradation rates of 2-methylisoborneol (MIB) and geosmin through sand filters and in bioreactors, Chemosphere 66, 2210-2218.

IWA, 2012, International Statistics for Water Services, Information every water manager should know, International Water Association, Special Group, Statistics and Economics.

Janniche, G. S., Lindberg, E., Mouvet, C., Albrechtsen, H.-J., 2010. Mineralization of isoproturon, mecoprop and acetochlor in a deep unsaturated limestone and sandy aquifer, Chemosphere 81, 823-831.

Jupiter, 2013. Water analysis - Kerteminde Forsyning- Vand A/S (Kerteminde net) (In Danish). The Geological Survey of Denmark and Greenland - GEUS, Denmark. http://www.geus.dk/jupiter/vandkvalitet-dk.htm (accessed 25.11.2013).

Lytle, D. A., Sorg, T. J., Wang, L., Muhlen, C., Rahrig, M., French, K., 2007. Biological nitrification in a full-scale and pilot-scale iron removal drinking water treatment plant, Journal of Water Supply: Research and Technology-AQUA 56.2, 125-136.

Mouchet, P., 1992. From conventional to biological removal of iron and manganese in France, Journal American Water Works Association 84 (4), 158-167.

Rittmann, B. E., Tang, Y., Meyer, K., Bellamy, W. D., Nerenberg, R. (2012). Biological Processes. Chapter 17 in Water Treatment Plant Design, $5^{\text {th }}$ edition, S. J. 
Randtke and M. B. Horsely, editors, American Water Works Association, Denver, CO.

Suty, H., De Traversay, C., Cost, M., 2004. Applications of advanced oxidation processes: present and future, Water Science and Technology, 49 (4), 227-233.

Tekerlekopoulou, A. G., Pavlou, S., Vayenas, D. V., 2013. Removal of ammonium, iron and manganese from potable water in biofiltration units: a review, Journal of Chemical Technology and Biotechnology 88, 751-773.

The Danish Ministry of the Environment, 2013. Pesticide statistics 2012, treatment frequency and pesticide load based on sales statistics and application data (In Danish). The Danish EPA, The Danish Ministry of the Environment, Denmark. http://www2.mst.dk/Udgiv/publikationer/2013/10/978-87-93026-49-0.pdf (accessed 04.12.2013).

Toräng, L. N., Albrechtsen, H.-J., 2003. Shifts in biodegradation kinetics of the herbicides MCPP and 2,4-D at low concentrations in aerobic aquifer materials, Environmental Science and Technology 37 (14), 3095-3103.

Tuxen, N., Tüchsen, P. L., Rügge, K., Albrechtsen, H.-J., Bjerg, P. B., 2000. Fate of seven pesticides in an aerobic aquifer studied in column experiment, Chemosphere 41, 1485-1494.

Winter, L., Linde, J. J., Winter, H., 2003. Water distribution technology (in Danish), Polyteknisk Forlag, 3rd edition, Denmark.

Zearley, T. L., Summers, R. S., 2012. Removal of trace organic micropollutants by drinking water biological filters, Environmental Science and Technology 46, 9412-9419.

Zuehlke, S., Duennbier, U., Heberer, T., 2007. Investigation of the behavior and metabolism of pharmaceutical residues during purification of contaminated ground water used for drinking water supply. Chemosphere 69, 1673-1680. 